\title{
Optimal mapping of terrestrial gamma dose rates using geological parent material and aerogeophysical survey data
}

\author{
B. G. Rawlins ${ }^{a, *}$, C. Scheib ${ }^{a}, A \cdot$ N. Tyler $^{b}$ And D. Beamish ${ }^{a}$ \\ ${ }^{a}$ British Geological Survey, Keyworth, Nottingham NG12 5GG, UK \\ ${ }^{\mathrm{b}}$ School of Biological and Environmental Sciences, University of Stirling, Stirling FK9 \\ $4 L A, U K$
}

${ }^{*}$ Corresponding author: B. G. Rawlins

British Geological Survey

Keyworth

Nottingham NG12 5GG

UK

phone: +44 (0) 1159363140

Fax: +44 (0) 1159363100

e-mail: bgr@bgs.ac.uk 


\section{Illustrated contents entry}

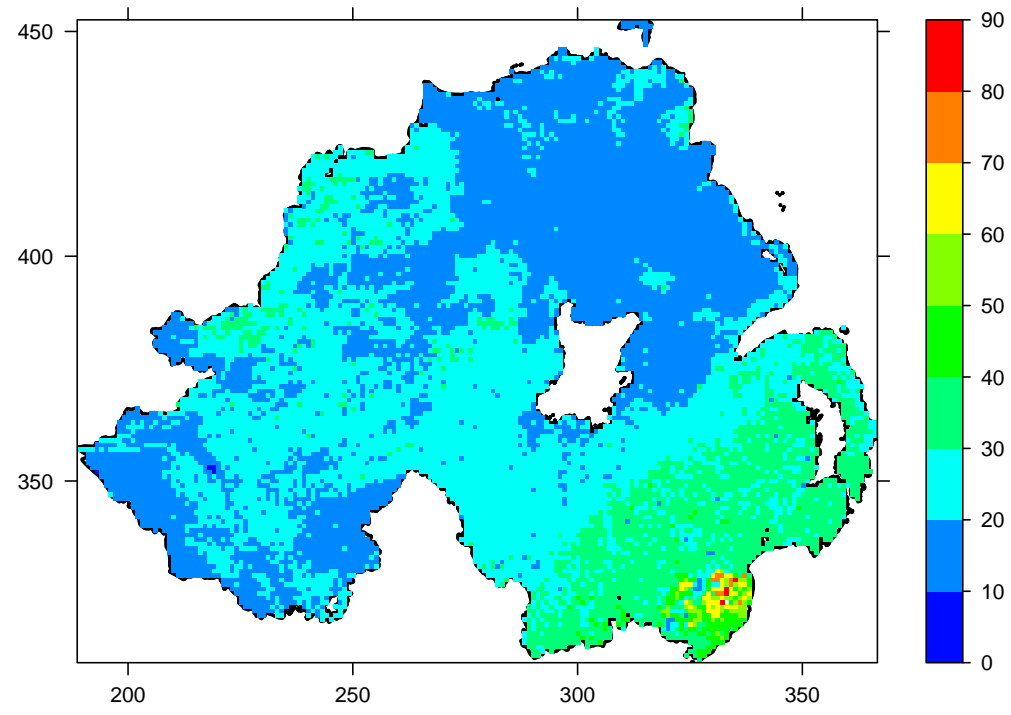

This optimal map of outdoor terrestrial gamma dose rate $\left(\mathrm{nGy} \mathrm{h}^{-1}\right)$ across Northern Ireland combines in situ measurements and dose estimates from a national scale, airborne radiometric survey. 


\section{Abstract}

Regulatory authorities need ways to estimate natural terrestrial gamma radiation dose rates $\left(\mathrm{nGy} \mathrm{h}^{-1}\right)$ across the landscape accurately, to assess its potential deleterious health effects. The primary method for estimating outdoor dose rate is to use an in situ detector supported $1 \mathrm{~m}$ above the ground, but such measurements are costly and cannot capture the landscape-scale variation in dose rates which are associated with changes in soil and parent material mineralogy. We investigate the potential for improving estimates of terrestrial gamma dose rates across Northern Ireland $\left(13542 \mathrm{~km}^{2}\right)$ using measurements from 168 sites and two sources of ancillary data: i) a map based on a simplified classification of soil parent material, and ii) dose estimates from a nationalscale, airborne radiometric survey. We used the linear mixed modelling framework in which the two ancillary variables were included in separate models as fixed effects, plus a correlation structure which captures the spatially correlated variance component. We used a cross-validation procedure to determine the magnitude of the prediction errors for the different models. We removed a random subset of 10 terrestrial measurements and formed the model from the remainder $(n=158)$, and then used the model to predict values at the other 10 sites. We repeated this procedure 50 times. The measurements of terrestrial dose vary between 1 and $103\left(\mathrm{nGy} \mathrm{h}^{-1}\right)$. The median absolute model prediction errors $\left(\mathrm{nGy} \mathrm{h}^{-1}\right)$ for the three models declined in the following order: no ancillary data (10.8) > simple geological classification (8.3) > airborne radiometric dose (5.4) as a single fixed effect. Estimates of airborne radiometric gamma dose rate can significantly improve the spatial prediction of terrestrial dose rate. 


\section{Introduction}

Exposure to natural, gamma radiation has deleterious effects on health by causing damage to nuclear DNA. ${ }^{1}$ Regulatory authorities need effective ways to improve estimates of exposure to natural radiation, which accounts for more than $80 \%$ of the total dose to which humans are typically exposed. Typically half of this natural radiation is related to radon gas and its decay products. Terrestrial gamma radiation contributes on average $13 \%$ of the average annual dose to the UK population. ${ }^{2}$ Exposure to terrestrial gamma radiation varies widely across the landscape, largely due to geological variation of naturally occurring radioactive materials in rocks, soils and in building materials. The mineralogical composition of the upper $1 \mathrm{~m}$ of the land surface is largely controlled by the soil parent material (PM) - the combination of bedrock or overlying superficial (Quaternary) deposits where present. Groups of PM account for a large proportion of the variation in the concentrations of the three dominant gamma emitting radionuclides (potassium $(\mathrm{K})$, thorium $(\mathrm{eTh})$ and Uranium $(\mathrm{eU})$ ), particularly in recently glaciated landscapes where the geochemistry of the soil and PM are closely associated. ${ }^{3}$ At large scales (e.g. $>1000 \mathrm{~km}^{2}$ ), the spatial variation in absorbed dose rate will be greater than its temporal variation because dose rate is source-dominated. In other words, it largely reflects the gamma source rather than the temporal variations in attenuation of the source due to variations in soil and atmospheric conditions.

Measurements of absorbed dose rates in air $\left(\mathrm{nGy} \mathrm{h}^{-1}\right)$, which express gamma ray intensity from radioactive materials in the earth and atmosphere, are typically undertaken using an in situ detector supported $1 \mathrm{~m}$ above the ground. Due to constraints of both time and cost, only a limited number of ground-based measurements can be undertaken across the landscape which cannot capture the spatial variation in absorbed dose rates. For example, in a survey across the UK a total of 128 measurements were undertaken, ${ }^{4}$ a sampling density of around one site per $2000 \mathrm{~km}^{2}$, which is insufficient to account for the variation in PM groups across this landscape. Estimates of absorbed dose based on interpolation for locations where measurements have not 
been undertaken will be subject to a substantial level of uncertainty.

It may be possible to significantly reduce these uncertainties using additional sources of landscape-scale data. Such approaches have been applied widely in the digital soil mapping community ${ }^{5}$ where covariates are often used within a geostatistical framework to account for the spatial variation in soil properties. One such covariate is measurement of natural emissions of gamma radiation from aerogeophysical surveys flown at low altitudes which cover large areas. Although terrestrial and airborne measurements are likely to be correlated, they will not estimate the same dose rate because: i) measurements will be undertaken at different times with differing atmospheric pressures and so gas fluxes from the ground will vary, ii) they have different measurement supports (the size and shape - in three dimensions - of the volume of material constituting the source of the gamma radiation for which a single measurement is determined) and, iii) corrections for cosmic sources may be somewhat different.

To our knowledge, low spatial resolution terrestrial measurements of gamma radiation dose $\left(\mathrm{nGy}^{-1}\right)$ have not previously been compared to high-resolution, airborne estimates of gamma radiation to investigate whether the latter could be used as ancillary variables to map the former with smaller prediction errors. Such an approach requires geostatistical techniques in which optimal spatial predictions of a primary property - terrestrial dose rate - are made using both primary measurements and secondary sources. The linear mixed modelling framework has been successfully applied to explain variations in airborne radiometric estimates of $\mathrm{K}$ concentration in the soil across part of central England based on variations in soil geochemistry and PM. ${ }^{6}$ and to improve spatially explicit estimates of soil organic carbon concentration in soils across northern Ireland. 7

In this paper we compare data from two sets of terrestrial dose measurements ${ }^{8,4}$ with measurements of airborne gamma radiation across all of Northern Ireland. 9 We explore the relative importance of soil PM in determining gamma emissions from $\mathrm{K}$, eTh and eU. We use geostatistical models to compare the magnitude of errors 
in estimating terrestrial gamma dose rate at unsampled locations by utilising: i) the original terrestrial survey data, ii) a simple geological classification and, iii) the airborne survey data. We undertake this analysis using a cross-validation procedure so that prediction errors could be compared. We comment on the implications of our findings for mapping adsorbed dose rate at landscape scales.

\section{Methods}

\section{Study region}

There is a wide range of bedrock types and Quaternary deposits across Northern Ireland which give rise to strong contrasts in near surface mineralogy, and thus concentrations of gamma emitting radionuclides (Figure 1). The north-eastern quadrant is dominated by Palaeogene basalt lava and lacustrine sedimentary rocks (Lough Neagh) at the surface, whilst the north-west is dominated largely by Dalradian psammite and semipelite. There are sedimentary outcrops of mudstone, sandstone and limestone across central to south-west Northern Ireland, which are mainly Carboniferous in age (with a Devonian component). The south-east comprises Ordovician and Silurian marine sedimentary rocks of the Southern-Uplands-Down-Longford Terrane with younger igneous complexes. Extensive Palaeogene granite bedrock forms the Mourne mountains to the south-east, close to the other felsic igneous complexes: the contemporaneous Sileve Gullion complex and the older Newry complex.

Extensive Quaternary deposits cover much of Northern Ireland including peat in upland areas, with large regions of superficial glacial till, glacial sands and gravels and river alluvium. We created a PM map of all of Northern Ireland by merging the bedrock and Quaternary geological maps in a GIS. This created a set of polygons, each having one of 65 unique parent material codes associated with it.

\section{Airborne radiometric survey}

The Tellus airborne geophysical survey of Northern Ireland was flown in 2005 and 2006 
and comprised more than $82000 \mathrm{~km}$ of flight lines. High-resolution radiometric data were acquired with an Exploranium GR820 256-channel NaI(Tl) gamma spectrometer system of four downward (32 litres) and one upward looking (8 litres) crystal sets. Data from the sensor were recorded every second corresponding to approximately 60-m intervals in the direction of flight. Survey lines were spaced $200 \mathrm{~m}$ apart with flight lines oriented at $345^{\circ}$ and $165^{\circ}$. The aircraft flew $56 \mathrm{~m}$ above ground in rural areas, but higher $(244 \mathrm{~m})$ above elevated structures and urban areas. The ground area or 'footprint', from which most of the radiation recorded comes, has the form of an ellipse elongated in the direction of flight. For example, at $56 \mathrm{~m}$ above the ground, $75 \%$ of the measured radiation comes from an ellipse with a major diameter of $220 \mathrm{~m}$ in the flight direction and minor diameter of $150 \mathrm{~m} \cdot{ }^{13} \mathrm{~A}$ complete description of the airborne geophysical systems deployed and the processing methods used is given by Hautaniemi et al. ${ }^{14}$ Procedures for processing the airborne radiometric data were based on those described in the reference manuals of the International Atomic Energy Authority ${ }^{15}$ and the Australian Geological Survey Organisation. ${ }^{16}$ The processing included corrections for aircraft and cosmic background radiation, altitude of the aircraft and spectral interactions. Gamma radiation measured by the airborne system comes from a thin surface layer of about $30 \mathrm{~cm}$ in rock, rather more in less dense, unconsolidated material such as mineral soil. Estimated activities of ${ }^{137} \mathrm{Cs}$ were also determined, based on a full spectrum processing. ${ }^{9}$ The corrected count rates were used to estimate the concentration of three natural radioelements within the conventional energy ranges: potassium $(\mathrm{K}, 137-157 \mathrm{MeV})$, equivalent uranium (eU, derived from $\left.{ }^{214} \mathrm{Bi}, 166-186 \mathrm{MeV}\right)$ and equivalent thorium (eTh, derived from $\left.{ }^{208} \mathrm{Tl}, 241-281 \mathrm{MeV}\right) \cdot{ }^{15,17}$ The survey yielded $c a$. 1.2 million values for $\mathrm{K}(\%)$, eTh $\left(\mathrm{mg} \mathrm{kg}^{-1}\right)$ and $\mathrm{eU}\left(\mathrm{mg} \mathrm{kg}^{-1}\right)$ and activities of ${ }^{137} \mathrm{Cs}$ $\left(\mathrm{kBq} \mathrm{m}^{-2}\right)$. Total gamma dose rate $\left(\mathrm{nGy} \mathrm{h} \mathrm{h}^{-1}\right.$ was then computed from the total count rate, which included the activities of of the three naturally occuring elements $(\mathrm{K}$, eTh, and eU) and also ${ }^{137} \mathrm{Cs}$.

To assess the relative importance of PM in determining the concentration of each 
of the three gamma-emitting elements $(\mathrm{K}, \mathrm{eTh}$ and $\mathrm{eU})$ plus dose rate, we assigned a code to every airborne survey site based on the 65 main types of PM (described above). We explored these data by constructing box and whisker plots for each of the three elements (K, eTh and eU) and also dose rate using the PM codes as the classes. In each case we calculated the proportion of variance accounted for by the PM classification using one-way ANOVA. For the purpose of producing a map of terrestrial gamma dose rate incorporating the airborne estimates we used the linear mixed modelling framework (see below). For each node on a one kilometre grid across all of the land surface of Northern Ireland we calculated the average of the nearest eight airborne dose estimates and used these as a fixed effect for prediction at the grid nodes.

\section{Terrestrial dose rate survey data}

In 1989, a nation-wide survey of terrestrial gamma outdoor dose rates was conducted across Northern Ireland ${ }^{8}$ at 158 sites. Measurements were taken from each $10 \mathrm{~km}$ square of the Ordnance Survey grid throughout Northern Ireland using a Mini-Instruments Environmental Monitor Type 6-80 with an energy compensated Geiger-Muller tube MC-71 at a height of $1 \mathrm{~m}$ above the ground. For use in this present study, measurements of corrected terrestrial gamma dose rate $\left(n G y h^{-1}\right)$ were taken from this published report and georeferenced using the associated Irish National Grid coordinates. ${ }^{8}$ for use in our study.A further ten measurements of terrestrial gamma dose rate for sites across Northern Ireland were available for sites that were part of the UK Soil and Herbage Survey. ${ }^{4}$ Both sets of terrestrial measurements were pre-corrected for cosmic radiation. The methods from these two surveys were sufficiently similar for the results to be combined into a single dataset of measurements at 168 sites (Figure 2).

First we assigned each terrestrial survey location a PM code using the 65-fold classification described previously. We then simplified these PM codes using expert knowledge to form a set of aggregated classes. For example, peat deposits typically contain small quantities of mineral material and so have low total gamma dose rates. 
Where peat deposits have been mapped they are more than $1 \mathrm{~m}$ deep, so such sites were assigned to the single class 'peat'. Similar rules were established to aggregate the classes, forming an initial set of 11 . These were given codes which partly related to their origin; 'BASA'=basalt, 'TILL'= glacial till, 'SDST'= sandstone, 'ALV'=alluvium, etc. Any remaining PM groups more difficult to aggregate were grouped in a mixed class with the code 'MIX'.

\section{Comparison of terrestrial and airborne dose measurements}

The sample support - the length, area or volume across which each sample measurement is made - were different for the terrestrial and airborne gamma surveys. For the former it was an area of a few metres and much larger for the latter as described above. In addition, their locations were not coincident. To estimate the airborne gamma dose rate at the terrestrial survey sites (Figure 2) we calculated the average of the nearest airborne survey sites. To identify the neighboring airborne survey locations we used the ann function in the yaImpute package ${ }^{18}$ in the $\mathrm{R}$ environment. ${ }^{19}$ We calculated the average of the nearest 5, 8 and 10 neighbours. The average of 8 neighbours had the strongest linear (Pearson) correlation $(r=0.8)$ with the terrestrial survey dose rates (see Figure 3) and so we used these data in our subsequent analyses.

\section{Geostatistical analysis using the linear mixed model}

We wished to explore to what extent geological class or airborne estimates of dose rate could account for the spatial variation in terrestrial gamma dose rates. For this purpose we used the linear mixed model, which we can write as

$$
\mathbf{z}=\mathbf{X} \boldsymbol{\tau}+\mathrm{Y} \boldsymbol{\eta}+\varepsilon
$$

Here the vector $\mathbf{z}$ contains our $\mathrm{n}$ observations of terrestrial gamma dose rate. Matrix $\mathrm{X}$ is an $n \times p$ design matrix that associates each of the $\mathrm{n}$ observations with a value of each of the $\mathrm{p}$ fixed effects, here a set of dummy variables that identify the parent 
material class at each site or airborne gamma dose rates or both. The vector $\boldsymbol{\tau}$ contains the $p$ fixed-effect coefficients. The vector $\boldsymbol{\eta}$ contains $q$ random effects, realizations of a variable $\eta$, that are associated with the $n$ observations by the $n \times p$ design matrix $(\mathbf{Y})$, which here is the identity matrix and $n=q$. We assume that $\eta$ is a spatially correlated random variable and $\varepsilon$ is a vector of independent random errors. These terms are independent of each other, and so we may write

$$
\left[\begin{array}{l}
\boldsymbol{\eta} \\
\boldsymbol{\varepsilon}
\end{array}\right] \sim \mathcal{N}\left(\left[\begin{array}{l}
0 \\
0
\end{array}\right],\left[\begin{array}{cc}
\sigma^{2} \xi \mathbf{R} & \mathbf{0} \\
\mathbf{0} & \sigma^{2} \mathbf{I}
\end{array}\right]\right)
$$

where $\sigma^{2}$ is the variance of the independent error, $\xi$ is the ratio of the variance of $\eta$ to $\sigma^{2}$ and $\mathbf{R}$ is the correlation matrix of $\boldsymbol{\eta}$. Note that we make an explicit assumption that the random terms are jointly Gaussian. The term $\varepsilon$, the nugget, represents both independent measurement errors and variation that arises from processes that are spatially dependent over shorter distances than those that separate the closest pairs of sampling points. Under the assumption that $\boldsymbol{\eta}$ is drawn from a second-order stationary random process, the correlation matrix $\mathbf{R}$ will depend only on the relative locations of our observations given some specified correlation function $C(\cdot)$ with one or more parameters that characterize the spatial dependence; so

$$
\mathbf{R}_{i, j}=\operatorname{Corr}\left[\boldsymbol{\eta}\left(\mathbf{s}_{i}\right), \boldsymbol{\eta}\left(\mathbf{s}_{j}\right)\right]=C\left(\mathbf{s}_{i}-\mathbf{s}_{j}\right) .
$$

The correlation function may be one of several authorized functions. ${ }^{20}$ The correlation function could be more complex with parameters that describe spatial anisotropy, but our exploratory analysis suggested that such elaboration was unnecessary. We estimated the parameters of the exponential function, which we represent by the vector $\theta$, along with $\sigma^{2}$ and $\xi$ by residual maximum likelihood (REML). The REML solution removes dependence of the estimates of the parameters in $\theta$ on the fixed effects $\tau$ which are nuisance parameters in this problem and which would increase the bias of estimates based on maximum likelihood or method-of-moments. ${ }^{21}$ Once the variance parameters are estimated we can obtain estimates of the fixed effects $(\tau)$ by generalized least squares. More details are given elsewhere. ${ }^{22,23}$ 
Before fitting the linear mixed models, we undertook exploratory statistical analysis of the terrestrial and airborne survey gamma dose data. If data are strongly skewed (e.g. absolute skewness coefficients $>1$ ) this can present problems for geostatistical analysis because a variogram calculated from such data may be strongly biased. The skewness coefficient for the untransformed, terrestrial dose data showed some positive skewness (skewness coefficient=1.49). In deciding whether to transform these data prior to our geostatistical analyses we had to consider the other models we planned to fit. Specifically, when using the airborne survey data as a fixed effect, the correlation function is calculated from the set of terrestrial dose rate residuals which may be close to normally distributed. If this were the case, it may be preferable not to transform the data because we wish to make comparisons between the different models using data on the same scale. To investigate this further, we fit a simple, least squares model between the paired $(\mathrm{n}=168)$ airborne dose (predictor) and terrestrial dose rate (predictand) data; the residuals were close to normally distributed (skewness coefficient $=$ 0.56). We therefore chose to undertake all our analyses on the original, untransformed data to ensure that the results were consistent and comparable.

We used the lme function in the $\mathrm{R}$ package $n l m e^{24}$ which fits linear mixed models which has an option to include a spatial correlation structure. We fitted both spatial and exponential covariance models and selected one of these using the log likelihood statistic. The residual likelihood statistic is only comparable between models with common fixed effects. We found that the exponential correlation function was optimal for estimating the spatial structure of the terrestrial gamma dose rate data with a range of fixed effects. The following fixed effects models were tested for the prediction of the terrestrial gamma dose rate:

1. The mean value only.

2. The mean value plus parent material class.

3. The mean value plus the airborne gamma dose rate $\left(n G y h^{-1}\right)$. 
4. The mean value plus airborne gamma dose rate $\left(\mathrm{nGy}^{-1}\right)$ plus parent material class.

The decision on whether to consider both airborne dose rate and parent material as fixed effects was made by comparing the model fits (in this case by maximum likelihood because likelihood estimates for two models by REML are not directly comparable) by reference to their log-likelihood ratio using the ANOva command in $\mathrm{R}$. The result $(P$ value $=0.18$ ) suggested that there was no basis for inclusion of both fixed effects so the fourth model in the list above is not considered further.

We compared the performance of the three different models using cross validation. We selected a random subset of 158 from the total 168 sites to build each of the models, and then estimated the dose rates at the remaining 10 sites. We repeated this procedure 50 times which gave 500 predictions that we compared to the measured values by calculating the absolute error. We then calculated the mean absolute error (MAE) and median absolute error (MedAE) and the bias for the estimates $(n=500)$ for each model. Using the airborne data as a fixed effect (model 3 above), we created an optimal map of terrestrial dose rate across all of Northern Ireland by estimating values on a $1 \mathrm{~km}$ grid using this model; the empirical, best least squares unbiased predictor or E-BLUP. ${ }^{23}$

\section{Results and discussion}

The summary statistics for terrestrial and airborne dose rates (Table 1) show that there is a positive bias to the distribution of the latter compared to the former; both the median and the maximum are larger. This may be in part be explained by differences in the procedures for estimating dose used in the terrestrial and airborne systems, and perhaps also the more complete coverage of the airborne survey; remote areas were not accessed by the ground based survey.

Based on a one-way ANOVA, classes of the original parent material map account for large proportions of the variance for each of the concentrations of the three 
radiogenic elements and dose rate, estimated from the airborne survey: $47 \%(\mathrm{~K}), 44 \%$ (eTh), 22\% (eU) and 52\% (dose). The relationship between each of these variables and 15 PM classes - selected to represent a broad range of mineralogy - is shown in Figure 4 as a box and whisker plot. There are clear differences between the distributions for many of these classes. For example, areas with sandstone and granitic bedrock have amongst the largest median $\mathrm{K}$ and $\mathrm{eTh}$ concentrations which accounts for the larger dose estimates over these lithologies. By contrast, basalt bedrock has low concentrations of all three gamma emitting elements - particularly where this is covered by peat deposits (Figure 4).

\section{Models and cross-validation}

The parameters for the fixed effects in each of the three models are shown in Table 2; the parameters of the spatially correlated components are shown in Table 3. Where airborne survey data are not included in the model, the PM classes with the most significance for predicting terrestrial dose rate are basalt bedrock and superficial peat; these have the smallest $P$-values (Table 2). The airborne survey data are substantially more significant $(P$-values $<0.0001)$ than the PM codes for predicting terrestrial dose rate. In each case, a substantial component of variance is captured by the spatial correlation structure. The fixed effects capture a substantial proportion of the variance in terrestrial dose rate.

The results of the cross-validation $(n=500)$ in predicting terrestrial dose rate are summarised in Table 4. The mean and median absolute predictions errors, according to inclusion of fixed effects in the model,decline in the following order: mean value> mean value $+\mathrm{PM}>$ mean value + airborne $>$. The simple geological classification results in a modest reduction in the MedAE for dose prediction; declining from 10.8 to $8.29 \mathrm{nGy} \mathrm{h}^{-1}$. A greater reduction in prediction error results on including the airborne dose estimates (MedAE $=5.39 \mathrm{nGy} \mathrm{h}{ }^{-1}$ ). The bias in the prediction errors also declines in the same order as for the prediction errors reported above; the smallest prediction 
bias is for the model in which airborne dose data are included as a fixed effect.

\section{Optimal map of terrestrial gamma dose rate}

The map of terrestrial gamma dose rate (Figure 5) provides a far greater level of detail than the interpolation of the data values presented in the original report on terrestrial gamma dose rates. ${ }^{8}$ The largest dose rates are associated with the granite bedrock of the Mourne mountains and the arenites across the south-eastern part of Northern Ireland (Figure 1). The smallest dose rates occur across the area of basalt bedrock, where the common occurrence of superficial, organic peat deposits dilutes the gamma signal from the minerals derived from the underlying rock.

Our study demonstrates that using a simplified map delineating twelve classes of PM can significantly improve the estimation of terrestrial gamma dose. The relationships between PM and terrestrial gamma dose may be quite different in landscapes which have been subject to longer (geological) periods of weathering such as tropical regions, and in such environments the distribution of geological parent materials may be less effective in accounting for variations in gamma dose. In some areas, human exposure to naturally occurring radioactive materials may be increased as a result of mining and transportation of raw materials. This technological enhancement of naturally occurring radioactive materials (TENORM) may result as a by-product of a variety of industrial and other activities including mining, extracting, concentrating, processing or combusting raw materials containing naturally occurring radioactive materials. ${ }^{25}$ Including the distribution of PM to improve mapping of terrestrial dose cannot account for the occurrence and distribution of TENORM.

Our findings show that terrestrial gamma dose rates across much of Northern Ireland are generally small $\left(<30 \mathrm{nGy} \mathrm{h}^{-1}\right)$. High-resolution maps of gamma dose rate are likely to be of most use for regulatory authorities in areas where dose rates are greatest $\left(>60 \mathrm{nGy} \mathrm{h} \mathrm{h}^{-1}\right)$. Our study shows that airborne radiometric is likely to be the most effective covariate for enhancing maps of terrestrial dose rate for a smaller set of 
ground-based measurements.

Most of the primary legacy data used in our study were a set of 158 terrestrial gamma dose measurements undertaken in 1989 and published as a paper report which included the grid coordinates of each site. ${ }^{8}$ Our study highlights the importance of ensuring that such legacy data are available so that new datasets may be combined with them to generate enhanced outputs - such as our optimal map of terrestrial dose rate.

\section{Conclusions}

The main findings from our study are:

1. A map of geological parent material classes across all of Northern Ireland accounted for $52 \%$ of the variation in gamma dose rate estimated from an aerogeophysical survey. Those areas with the largest estimated dose rates had geological parent materials with greater concentration of gamma emitting elements. For example, some of the largest dose rates were observed over areas of granite, the soils over which have large concentrations of both $\mathrm{K}$ and eTh.

2. Using a series of terrestrial gamma dose rate measurements ( $\mathrm{Gy} \mathrm{h}^{-1}: n=168$ ) across all of Northern Ireland, a simplified PM map (n=12 classes) significantly improved their estimation using a statistical model and a cross-validation procedure. The median absolute error in estimated dose rate declined from 10.8 (no PM classification) to $8.29 \mathrm{nGy} \mathrm{h}^{-1}$ (with a PM map).

3. Incorporating the estimated dose rates from the airborne survey led to a greater reduction in the error of estimating terrestrial gamma dose rate. The median absolute error from the cross-validation analysis after applying the linear mixed model was $5.39 \mathrm{nGy} \mathrm{h}^{-1}$. The map of terrestrial gamma dose rate across all of Northern Ireland incorporating the airborne data shows a resolution which would not be possible based on ground-based measurements because the latter are too 
costly to collect at the resolution of the airborne estimates.

4. Terrestrial gamma dose rates across much of Northern Ireland are generally small $\left(<30 \mathrm{nGy} \mathrm{h}{ }^{-1}\right)$.

\section{Acknowledgements}

The Tellus surveys were financed in Northern Ireland by the the Department of Enterprise, Trade and Investment and the 'Building Sustainable Prosperity' scheme of the Rural Development Programme. This paper is published with the permission of the Executive Director of the British Geological Survey (Natural Environment Research Council) and the Director of the Geological Survey of Northern Ireland.

\section{References}

1 UNSCEAR, 2006. Effects of Ionizing Radiation. United Nations Scientific Committee on the Effects of Atomic Radiation. UNSCEAR 2006 Report to the General Assembly with scientific annexes. United Nations, New York.

2 Hughes, JS, Watson, SJ, Jones, AL and Oatway, WB. 2005. Review of the radiation exposure of the UK population. J. Radiol. Prot., 25, 493-496.

3 Rawlins B.G., Webster, R. and Lister, T.R. 2003. The influence of parent material on top soil geochemistry in eastern England. Earth Surf. Proc. Land., 28, 13891409.

4 Tyler, A. N. and Copplestone, D. 2007. Preliminary results from the first national in situ gamma spectrometry survey of the United Kingdom. J Environ. Radioactiv, 96, 94-102.

5 McBratney, A. B., Mendona Santos, M.L. and Minasny, B. 2003. On digital soil mapping. Geoderma, 117, 3-52. 
6 Rawlins, B. G., Webster, R. and Lark, R. M. 2007. Understanding airborne radiometric survey signals across part of eastern England. Earth Surf. Proc. Land., 32, 1503-1515.

7 Rawlins, B. G., Marchant, B. P., Smyth, D., Scheib, C., Lark, R. M. and Jordan, C. 2009. Airborne radiometric survey data and a DTM as covariates for regional scale mapping of soil organic carbon across Northern Ireland. Eur. J. Soil. Sci., 60, 44-54.

8 Caulfield J. J. and Ledgerwood, F. K. 1989. Terrestrial gamma-ray dose rates out of doors in Northern Ireland. Department of the Environment for Northern Ireland, Environmental Monitoring Report No 2, Belfast, Northern Ireland.

9 Scheib, C. and Beamish, D. 2010 High spatial resolution observations of ${ }^{137}$ Cs in northern Britain and Ireland from airborne geophysical survey. J Environ. Radioactiv., 101, 670-680.

10 Mitchell, W. 2004. The Geology of Northern Ireland: Our Natural Foundation. Geological Survey of Northern Ireland, Belfast, 318pp.

11 Geological Survey of Northern Ireland, 1991. Geological map of Northern Ireland: Quaternary Edition. 1:250 000 scale (1st Edition). Belfast, Northern Ireland

12 Geological Survey of Northern Ireland, 1997. Geological map of Northern Ireland: Solid Edition. 1:250 000. 2nd (Edition). Belfast, Northern Ireland.

13 Pitkin, J. A. and Duval, J.S. 1980. Design parameters for aerial gamma-ray surveys. em Geophysics, 45, 427-439

14 Hautaniemi, H., Kurimo, M., Multala, J., Levniemi, H., Vironmki, J. 2005. The three in one aerogeophysical concept of GTK. In M.-L. Airo (Ed.), Aerogeophysics in Finland 19722004: Methods, System Characteristics and Applications, Geological Survey of Finland (2005), pp. 2174 Special Paper 39. 
15 IAEA, 1991. Airborne gamma ray spectrometer surveying. International Atomic Energy Agency, Technical Report Series, No. 323. Vienna, Austria.

16 Grasty, R.L. \& Minty, B.R.S. 1995. A guide to the technical specifications for airborne gamma-ray surveys. Australian Geological Survey Organisation: Record $1995 / 20$.

17 IAEA, 1993. Guidelines for radioelement mapping using gamma ray spectrometry data. International Atomic Energy Agency IAEA-TECDOC-1363. Vienna, Austria.

18 Crookston, Nicholas L.; Finley, Andrew O. 2007. yaImpute: An R Package for k-NN Imputation. Journal of Statistical Software. 23(10):1-16.

19 R Development Core Team (2009). R: A language and environment for statistical computing. R Foundation for Statistical Computing, Vienna, Austria. ISBN 3-900051-07-0, URL http://www.R-project.org.

20 Webster, R. and Oliver, M.A. 2007. Geostatistics for Environmental Scientists, 2nd edition. Wiley, Chichester.

21 Smyth GK, Verbyla AP. 1996. A conditional likelihood approach to residual maximum likelihood estimation in generalized linear models. Journal of the Royal Statistical Society, Series B 58: 565-572.

22 Lark RM, Cullis BR. 2004. Model-based analysis using REML for inference from systematically sampled data on soil. Eur. J. Soil. Sci., 55, 799-813.

23 Lark RM, Cullis BR, Welham SJ. 2006. On spatial prediction of soil properties in the presence of a spatial trend: the empirical best linear unbiased predictor (E-BLUP) with REML. Eur. J. Soil. Sci., 57, 787-799.

24 Pinheiro, J., Bates, D., DebRoy, S., Sarkar, D. and the R Core team (2009). nlme: Linear and Nonlinear Mixed Effects Models. R package version 3.1-96. 
25 Vearrier D, Curtis JA, Greenberg MI., 2009. Technologically enhanced naturally occurring radioactive materials. Clin. Toxicol., 47, 393-406. 


\section{List of Figures and Captions}

Figure 1 Simplified bedrock map of across Northern Ireland.

Figure 2 The spatial distribution of terrestrial gamma dose rate measurements from the Northern Ireland survey $(\mathrm{n}=158$; Caulfield and Ledgerwood, 1989) and the UK soil and herbage survey $(n=10$; Tyler and Copplestone, 2007).

Figure 3 Scatterplot of airborne and terrestrial gamma dose rate measurements for 168 terrestrial measurement sites across Northern Ireland. The airborne dose rates are the average of the eight airborne sites closest to each terrestrial site.

Figure 4 Box and whisker plot showing the estimated concentrations of the three gamma emitting elements $(\mathrm{K}$, eTh and $\mathrm{eU})$ and estimated dose rate in the upper part of the solum for 15 selected combinations of PM for all the airborne survey sites. The width of each box is proportional to the number of sites in each class. The PM codes refer to combinations of the Quaternary (TILL=till, ALV=alluvium, GSG=glacial sands and gravels, PEAT=peat) and specific bedrock (SDST=Quarry sandstone, PSSP=psammite and semi pelite, LMST=limestone, BASA=basalt, GRAN=Granite, COSD=conglomerate, LATU=Cromarty Sandstone, ROCK=a range of smaller bedrock types with no Quaternary deposit present) deposits.

Figure 5 Map of terrestrial gamma dose rate $\left(\mathrm{nGy} h^{-1}\right)$ across Northern Ireland on a 1-kilometre grid. The estimates were generated using a linear mixed model in which the fixed effects were the mean value (measured terrestrial dose) and measured airborne dose rate plus a spatially correlated component. Coordinates are kilometres on the Irish National Grid. 
419

421

\begin{tabular}{lcc} 
& Terrestrial gamma dose $\left(\mathrm{nGy}^{-1}\right)$ & Airborne gamma dose $\left(\mathrm{nGy}^{-1}\right)$ \\
\hline \multirow{2}{*}{${ }^{422} 2$} & 1.0 & $a_{-} 9.0$ \\
Meanimum & 23.2 & 33.3 \\
Median & 23.0 & 32.6 \\
Stanimum & 103 & 320 \\
Skewness & 13.3 & 22.5 \\
Number of sites & 1.49 & 1.19 \\
\hline \hline
\end{tabular}

Table 1 Summary statistics for surveys of terrestrial and airborne gamma dose rate across Northern Ireland.

${ }^{a}$ the greater uncertainties in the airborne measurements and the corrections applied to account for cosmic radiation and aircraft background can lead to negative estimates of dose rate

b includes data from the NI survey (Caulfield and Ledgerwood, 1989) and the UK soil and herbage survey (Tyler and Copplestone, 2007) 
428

Table 2 Parameter estimates of the fixed effects for four linear mixed models (see text) used for the estimation of terrestrial dose rate. The values shown are those based on a model fit to data from all 168 terrestrial dose sites.

\begin{tabular}{lcccc}
\hline Model parameters & Value & Std.Error & $t$-value & $P$-value \\
\hline a) mean only & & & & \\
Intercept & 24.7 & 6.43 & 3.85 & $2 \times 10^{-5}$ \\
\hline b) mean + PM class & & & & \\
a Intercept & 26.1 & 9.59 & 2.72 & 0.0075 \\
BASA & -11.6 & 4.12 & -2.81 & 0.006 \\
GRAN & -2.04 & 5.24 & -0.39 & 0.70 \\
GSG & 1.11 & 4.37 & 0.25 & 0.80 \\
LAT & -5.70 & 5.11 & -1.12 & 0.27 \\
PEAT & -10.2 & 4.38 & -2.32 & 0.02 \\
PSSP & -8.06 & 4.61 & -1.75 & 0.08 \\
ROCK & -2.20 & 4.06 & -0.54 & 0.59 \\
SDSM & 2.03 & 5.28 & 0.38 & 0.70 \\
SDST & -1.36 & 3.63 & -0.37 & 0.71 \\
TILL & -4.19 & 3.97 & -1.05 & 0.29 \\
MIX & -3.26 & 4.40 & -0.74 & 0.46 \\
\hline c) mean + airborne dose & & & & \\
Intercept & 9.36 & 4.43 & 2.11 & 0.0363 \\
b Air & 0.395 & 0.045 & 8.68 & $<0.0001$ \\
\hline \hline
\end{tabular}

${ }_{432}{ }^{a}$ the coefficient for the PM class ALV (alluvium) is not shown because all the other PM class intercept values are differences from the ALV coefficient. ${ }^{b}$ refers to inclusion of the airborne radiometric data as a fixed effect. 
435

436

438

439

Table 3 Parameter estimates of the spatially correlated variance components for four linear mixed models (see text) used for the estimation of terrestrial dose rate. The values shown are those based on a model fit to data from all 168 sites. In all cases an exponential spatial correlation model was selected.

\begin{tabular}{lccc}
\hline Model & Mean & Mean+PM & Mean+airborne \\
\hline range (metres) & 66416 & 40372 & 53266 \\
nugget variance & 52.4 & 38.9 & 43.0 \\
sill variance & 166 & 86.6 & 67.9 \\
\hline \hline
\end{tabular}


Table 4 Cross-validation statistics for estimation of terrestrial gamma dose rate $(n=500)$ using linear mixed models with different fixed effects. Ten sites were selected randomly from the full dataset $(n=168)$ and models were formed from data at the other 158 sites. Estimates of terrestrial gamma dose rate were then computed for the ten independent sites. The procedure was repeated 50 times to give a total of 500 estimates which were compared with the actual values to calculate mean absolute error (MAE), median absolute error (MedAE) and bias. PM refers to parent material class and airborne refers to the estimate of airborne radiometric dose rate.

Model $\quad \operatorname{MAE}\left(\mathrm{nGy} \mathrm{h}^{-1}\right) \quad \operatorname{MedAE}\left(\mathrm{nGy} \mathrm{h}^{-1}\right) \quad$ bias $\left(\mathrm{nGy} \mathrm{h}^{-1}\right)$




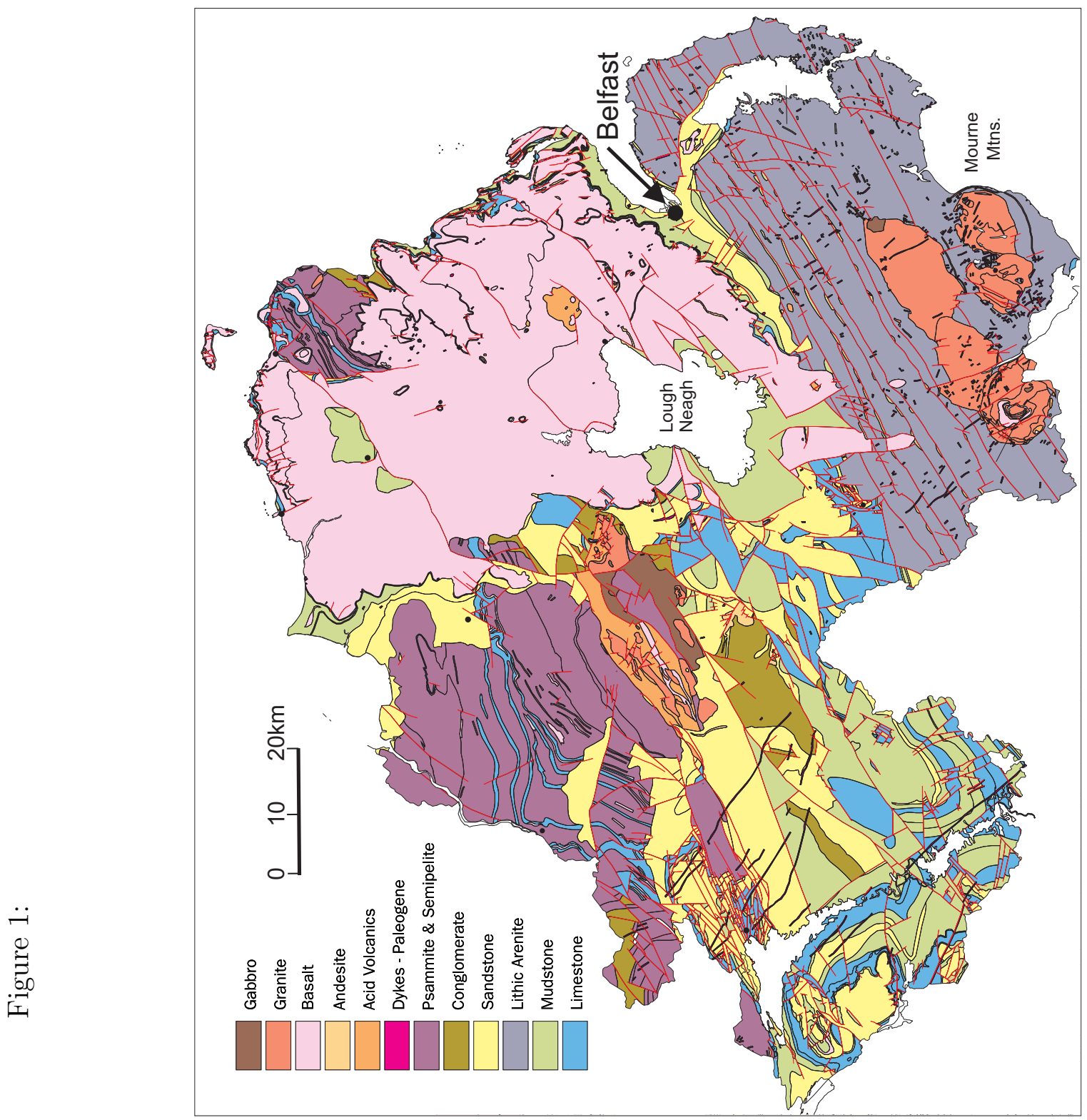


Figure 2:

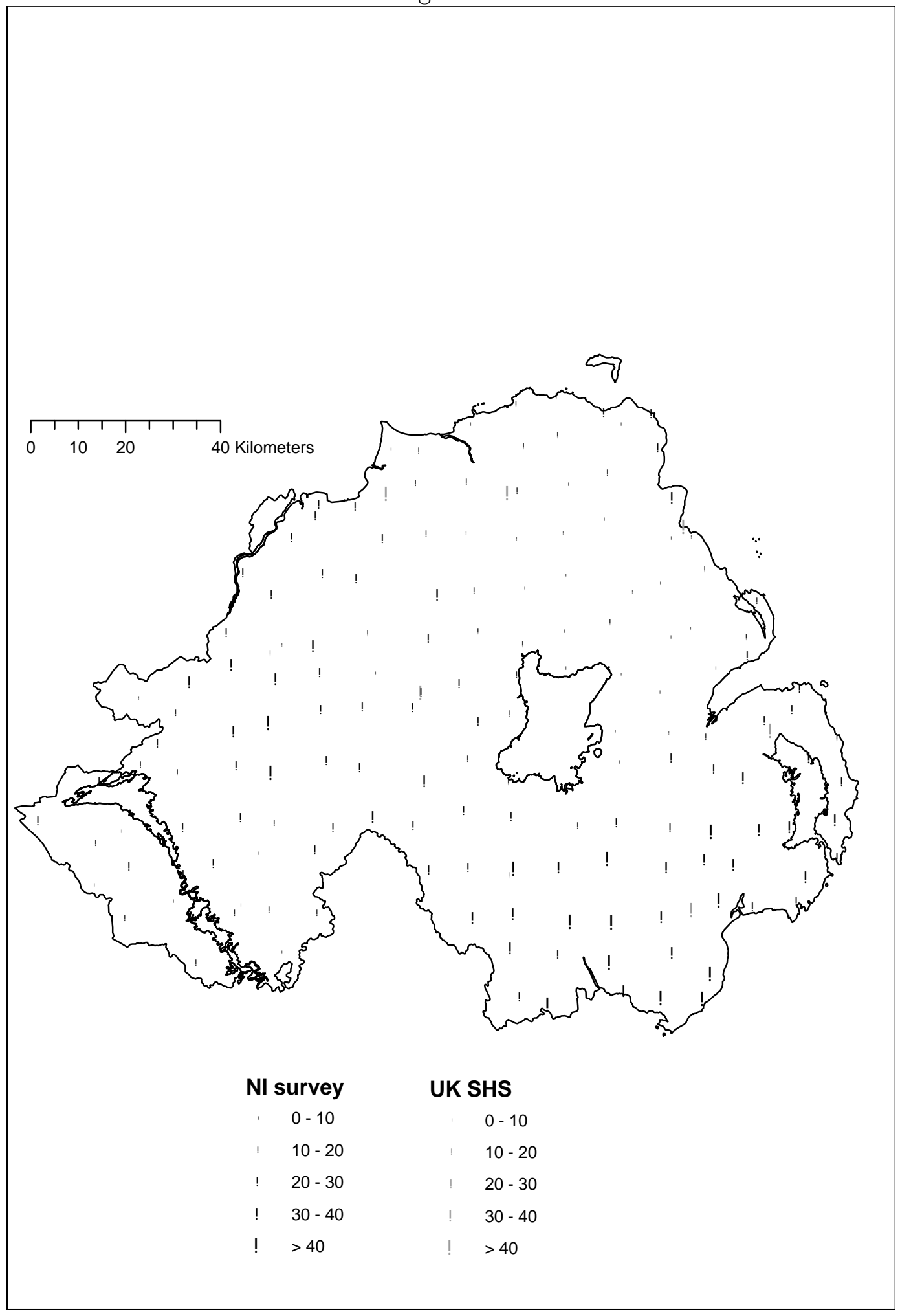


Figure 3:

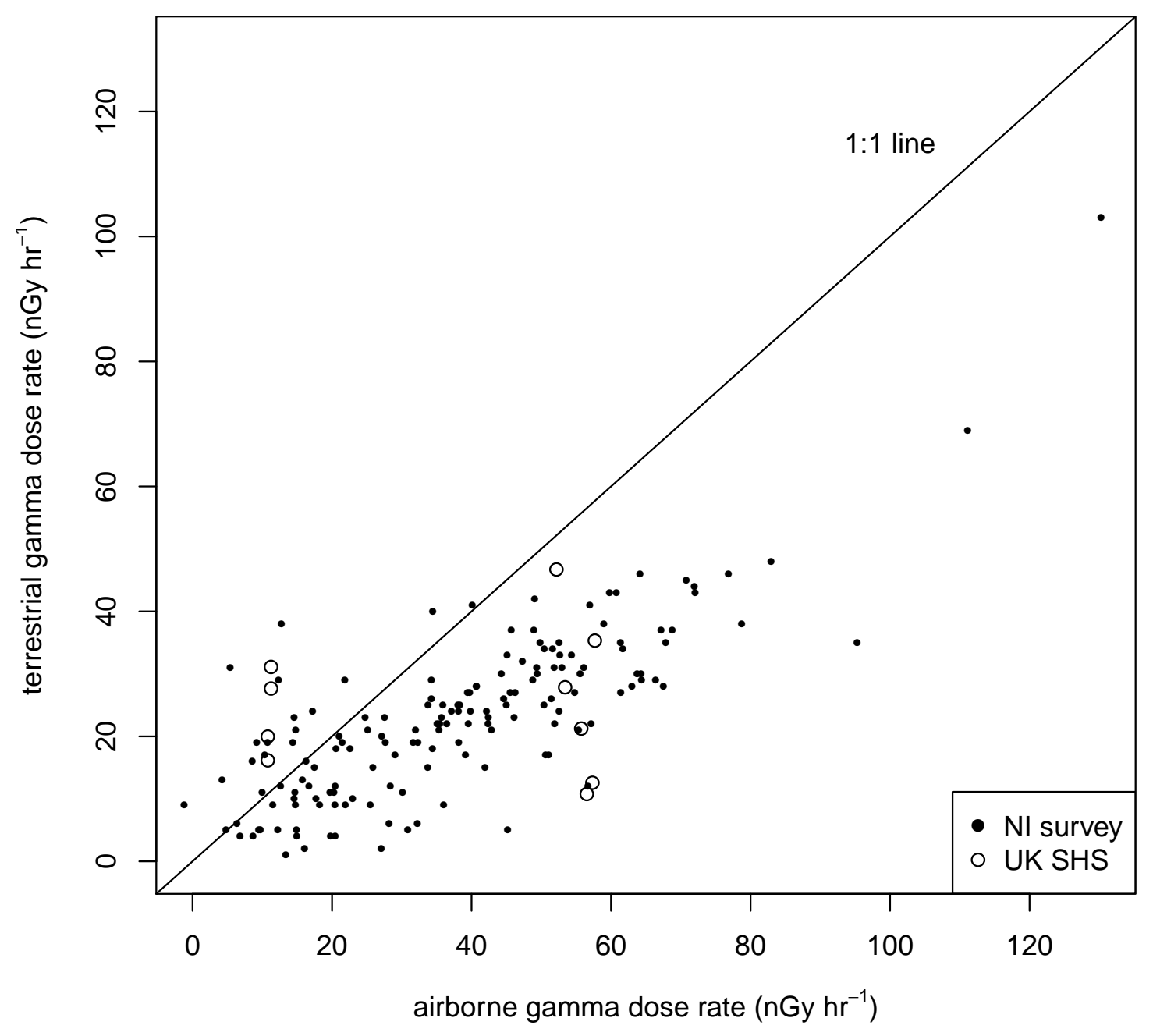



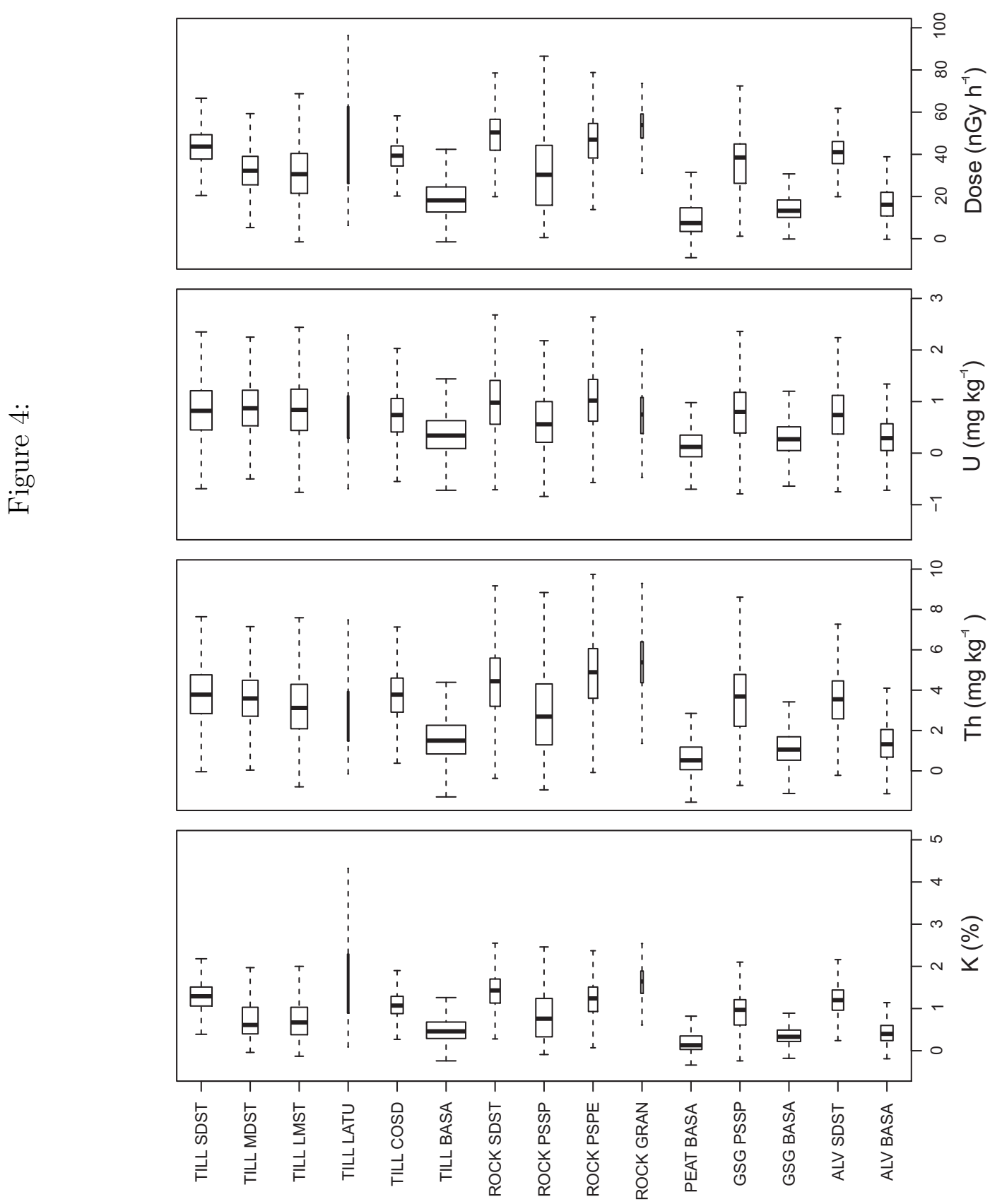
Figure 5:

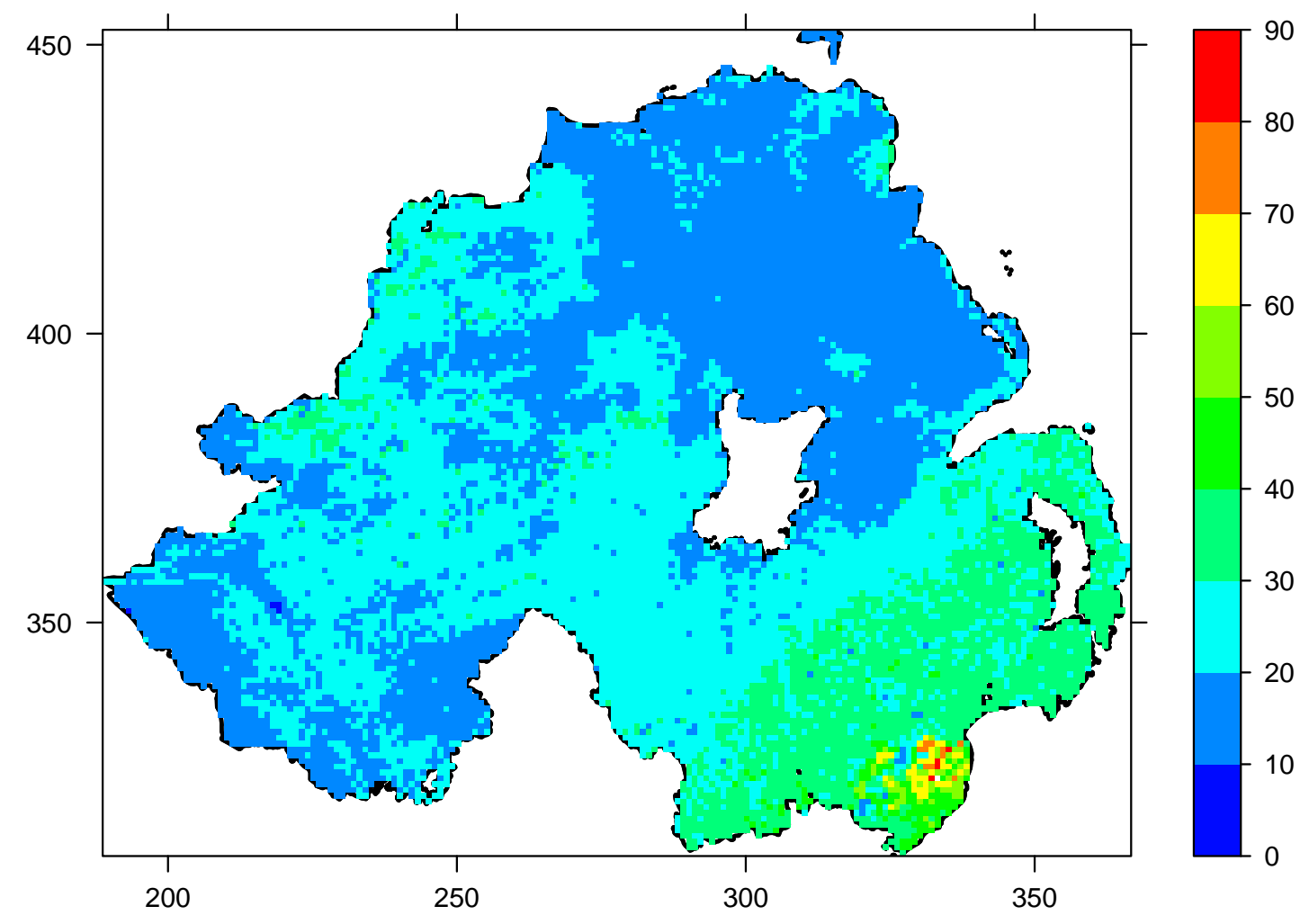

